\title{
Communication Experiences of Speech and Hearing Impaired Clients in Accessing Healthcare in Hohoe Municipality of Volta Region, Ghana
}

\author{
Prince Kubi Appiah, \\ Department of Family and Community Health, School of Public Health, \\ University of Health and Allied Sciences, Ho, Ghana

\section{Georgina Agartha Fenu,} \\ Department of Epidemiology and Biostatistics, School of Public Health, \\ University of Health and Allied Sciences, Ho, Ghana \\ Geoffrey Adebayo Asalu, \\ Wilson Mensah Dzata, \\ Department of Family and Community Health, School of Public Health, \\ University of Health and Allied Sciences, Ho, Ghana

\section{Duut Abdulai Bonchel,} \\ Department of Social Work, University of Ghana, Legon, Accra, Ghana

\section{Timay Ibrahim Abdul-Rahman,} \\ Department of Population and Behavioural Sciences, School of Public \\ Health, University of Health and Allied Sciences, Ho, Ghana

\section{Anthony Zunuo Dongdem,} \\ Department of Epidemiology and Biostatistics, School of Public Health, \\ University of Health and Allied Sciences, Ho, Ghana
}

Doi: 10.19044/esj.2018.v14n12p209 URL:http://dx.doi.org/10.19044/esj.2018.v14n12p209

\begin{abstract}
Background Access to healthcare for speech and hearing impaired clients can be difficult against the backdrop that healthcare providers are inadequately trained to work with Deaf clients whose primary mode of communication is sign language. Therefore, this study sought to explore communication experiences of deaf people and barriers affecting their access to healthcare in Hohoe municipality in Volta region of Ghana. Method: For this quantitative and qualitative cross-sectional study 40 participants were recruited through snowball sampling technique. Quantitative data was obtained through administration of semi-structured questionnaire to sixteen (16) willing participants. The information was triangulated with three (3) focus group discussions. The statistical software Epi Info version 7 and Stata version 11 was used to analyze the quantitative data and presented in graph
\end{abstract}


and tables. Thematic analysis was adopted for analyzing the qualitative data. Findings: Majority (93\%) of the study participants are deaf and 7\% being hard of hearing. Half (20) of them were above 30 years. Male to female participants in the study were equal. Thirty-five percent of participants had at least primary education and $10.0 \%$ had no formal education however $28 \%$ of them were employed. Gestures, sign language, assistance from a family member/friend, lip reading and writing are the various methods used by the deaf in communicating with healthcare providers. Family member/friends assistance and gestures were the most frequently used methods of communicating. Due to communication difficulties, they experience disparity, discriminations, neglect and delays in receiving healthcare from providers. Financial difficulties was also identified as barrier in accessing health. Conclusions: Access to healthcare for hearing impaired clients is important to achieve health equity. However challenging it can be, due to communication gaps, efforts must be made to ensure that this group receive adequate health care.

Keywords: Deaf client, healthcare, communication experience, Hohoe municipality

\section{Introduction}

Around $15 \%$ of the world's population are presented with disabilities, ranging from mild to severe, (WHO, 2011). The deaf are among these and deafness by WHO refers to the complete loss of hearing ability in one or two ears, (Kyle et al., 2013). The deaf lack the power of hearing for ordinary purposes of life. It is caused by congenital diseases acquired at birth or infections much later in life and other causes such exposure to loud noise, ageing, malformation of the inner ear (Breu, Guggenbichler, \& Wollmann, 2004). Deaf population is estimated to be $5 \%$ of world's population, with approximately one-third of these people over the ages of 65 years, whiles, in Ghana more than 260,000 people are deaf (Joshua, 2013). This group of people has a different mode of learning values and cultures, which gives them a special belief as a group. Because the group is mostly neglected, they tend to learn from their older deaf associates. The consequences of hearing and speech impairment leads to inability to understand speech sound, decreased capability to communicate, delay in language development, economic and educational backwardness, social isolation and stigmatization and hence affects health (Singh, 2015).

All individuals desire for sound health and this can only be achieved through quality healthcare, (Levesque, Harris, \& Russell, 2013), therefore, there is a need to ensure unrestricted access to all irrespective of one's age, race, gender, social status, economic status or physical status (disability` state) 
to healthcare, (Levesque et al., 2013). The physically challenged and disabled are equally eligible to access quality healthcare, however, the deaf have common and very unique barriers in accessing healthcare (Peterson-Besse, Walsh, Horner-Johnson, Goode, \& Wheeler, 2014). People with hearing and speech disabilities may have the same general care need as those without any disabilities, hence, it is important to provide equal access to the mainstream healthcare, (Kyle et al., 2013). The degrees of hearing loss array from slight to mild, moderate, moderately severe, severe or intense which can occur at any time during a person's life and can affect one or both ears and hence, each require different mode of communication, (Shuler \& Mistler, 2014).

In health, communication between patient and their healthcare provider is very essential but is usually hindered when patients are disable (deaf), creating hesitation in accessing healthcare, (Andrade, 2010). Hence, affecting the health status of the people and the population at large. Although medical education is to prepare physicians for the common issues they will face in practice, medical schools do not adequately teach the communication skills necessary to work with the people (being their patients or a caregiver) with hearing loss, (Barnett, 2002). Communication and learning among deaf are usually primarily through visual methods, and the use of Sign Language (Marschark \& Carol, 2007).

Furthermore, this group shares a common language, life experiences and belief that are usually different from the hearing society (Shuler \& Mistler, 2013). Yet, clinicians go through difficulties in interacting with them during consultation and is as a result of difficulty with communicating skills, lack of knowledge about clients' culture, language, and literacy level that can significantly impede the level of care received by the deaf (Shuler \& Mistler, 2013). The key to a successful communication with people with hearing and speech loss is the ability to adapt to the needs of their situation to allow them to express themselves aright, (Barnett, 1999, 2002). This calls for the need for healthcare providers to pay extra attention to deaf in the cause of their health seeking.

Access to healthcare can affect the health of deaf people hence, a call for action to provide better access to health services has been emphasized (Scholarworks \& Tarmey, 2007). Less effective communication, could result in negative effects which include difficulty in making appointments, patients anxiety and usually medication dosing errors, (Steinberg, Barnett, Meador, Wiggins, \& Zazove, 2005). It has become essential to find optimum strategic interventions to assimilate their needs into primary healthcare systems, and this needs to be prioritized in order to deliver effective healthcare to all (Kuenburg, Fellinger, \& Fellinger, 2016).

Access to healthcare services by deaf could be challenging because of their inability to communicate especially with the health personnel. The 
healthcare providers are insufficiently prepared to work with Deaf patients (a patient or a relative) whose primary mode of communication is sign language (Rodda \& Eleweke, 2002). This has captured the attention of the international health and development community on the health of people with disability. Thus barriers that people with disabilities face in accessing health services at a variety of levels are now being addressed although much need to be done especially in the developing countries, (WHO, 2011). In the Hohoe municipality, the deaf population is estimated to be $1,288,(33.9 \%)$ of which 635 live in the urban part of Hohoe and 653 in the rural area, (Hohoe municipality, 2014).

Although there is an increase in population of deaf which calls for attention, less or insufficient literature is on hand to acquaint educators and doctors about the problems and needs of the deaf people (Barnett, 2002). Similarly, nurses report of facing communication difficulties when delivering care to hearing impaired patients (Steinberg et al., 2005). The current situation indicates that this minority group (deaf) is greatly disadvantaged in accessing health services, hence, health is not equitable for people with disabilities (Rodda \& Eleweke, 2002). In the light of this, the study was conducted in Hohoe Municipality to assess communication experiences of deaf clients and barriers preventing their access to healthcare.

\section{Materials and Methods \\ Study site}

The study was conducted in the Hohoe municipality of the Volta Region of Ghana. The municipality is divided into seven (7) Sub-Municipals. Hohoe is one of the seven sub-municipals and at the same time the Municipal's capital. It is located about 220 kilometers from Accra, the Nation's capital. The Municipal is located within longitude 0 degrees $15^{\circ} \mathrm{E}$ and 0 degrees $45^{\circ} \mathrm{E}$ and latitude 6 degrees $45^{\circ} \mathrm{N}$ and 7 degrees $15^{\circ} \mathrm{N}$ and lies almost in the heart of the Volta Region (Hohoe municipality, 2014).

There are about eighteen Community Health and Planning Services (CHPS) zones and health centers, one Reproductive and Child Health (RCH), one Health Centre and one Government hospital which serves a total population of 58,130 in 33 communities in Hohoe. The deaf population amounts to $1,288,(33.9 \%)$ of which 635 live in the urban part of Hohoe and 653 in the rural area (Hohoe municipality, 2014). The school of deaf and dumb for whole Volta region is in Hohoe Municipality.

The major source of water is pipe borne but there are few bore holes and a Dayi river which takes its source from the Akpafu ranges before entering the Volta Lake in the Kpando District. Houses in Hohoe are generally of the compound type except the newly developing ones which have western type of houses with modern facilities. 
The major economic activities with respect to commerce, trade and industry include trading services, agriculture, small scale processing and manufacturing. There are increasing number of hawkers on the streets of Hohoe. Commodities traded in Hohoe are principally food stuffs and general goods including manufactured goods. The urban-based activities are scattered throughout town and not conforming to any proper land use. The rural-based settlements are far away from town and mainly footpaths. There is a large population in the town settlement with fewer population in the rural settlements.

\section{Study Population}

The study population consisted of deaf from various communities in the municipality. Healthcare providers including doctors, nurses, OPD staffs and pharmacist from various health centers and hospitals were included in the study.

\section{Exclusion \& Inclusion Criteria}

All speech and hearing impaired clients who were 18 years and above, have stayed and lived in the municipality for 6 or more months, can use the sign language in communication and were willing to be part and to sign the consent form were included in the study. Those who could not sign or cannot talk for themselves were excluded from the study. However, all foreigners were excluded even when they have stayed in the municipality for the specified period.

\section{Study Design}

A cross-sectional quantitative and qualitative study was employed in assessing communication experiences of speak and hearing impairment clients in accessing healthcare in Hohoe Municipality.

$\mathbf{v}$

There was a total of 40 participants, and 3 focus group discussion with 10, 8, 6 members in each group. The remaining 16 in addition to 6 of the focus group members who were randomly selected were involved in administered semi-structured questionnaire to provide their responses.

\section{Sampling Method}

Hospital record review was adapted to trace the index of deaf participants. Snowball sampling method was then used to find and select the deaf participants.

\section{Data Collection Procedure}

Face-to-face in-depth interview using semi-structured questionnaire 
was adapted to generate quantitative data from the participants. The interview was conducted by the principal investigator with the help of a trained sign language interpreter.

Focus Group Discussion; Three (3) Focus group discussions were held for this study with group membership ranging from 6-10 individuals. The discussants were made to sit in a semi-circle fashion with the moderator (sign language expert) and the note taker in the middle. FGDs guides were used and the areas covered to generate information were mode of communication at a health facility, provider's attitude and barriers in accessing healthcare. During the FGDs, participants were given equal opportunity to contribute to discussions. Generally, the discussions lasted 60-90 minutes.

\section{Data Analysis}

Data entry and analysis on background characteristics and quantitative data was done using EPI DATA 3.1 and STATA 11.0 respectively. Data cleaning and validation was done to ensure data quality before analysis was carried out. Descriptive statistics such as frequencies and percentages presenting in graph and tables were used in describing the background characteristics and quantitative data. For qualitative data, the sign language expert who doubles as the moderator and interpreter translates signs into verbal words which was recorded by the note taker. The field notes were then carefully transform into data document. The data coded with short phrases to signify participants own expressions. After that, the coded data was summarized into themes.

\section{Ethical Issues}

Participation in the study conformed to the required ethical guidelines regarding the use of human subjects. The study was reviewed by the Ethical Review Board of the Ghana Health Services, Research and Development Division, Accra with protocol number GHS-ERC 42/10/2016. Permission was obtained from the Hohoe Municipal Hospital to use health records to trace index participant. Participation in the study was voluntary, and consent was sought from the participants.

\section{Results}

\section{Background Characteristics of Respondents}

There were 40 deaf participants who participated in the study. Twentyfour participated in the focus group discussion (FGD) and 16 other willing participants including 6 members of FGD responded to a questionnaire administered. Half $20(50 \%)$ of them were above 30 years, whiles there was an even distribution of male to female participants in the study. About 23 $(57.5 \%)$ of them were single. Some $18(45.0 \%)$ and $4(10.0 \%)$ of the 
participants have been able to attain secondary and tertiary education respectively, however, as high as $14(35.0 \%)$ and $4(10.0 \%)$ receive only primary and no education respectively. Only $11(27.5 \%)$ of the respondents were employed (Table 1).

Table 1: Demographic Characteristics of Respondents.

\begin{tabular}{lll}
\hline \multicolumn{1}{c}{ Variable } & Frequency $(\mathrm{n}=40)$ & Percentage (\%) \\
\hline Age Group & & \\
$<25$ & 11 & 27.5 \\
$25-30$ & 9 & 22.5 \\
Above 30 & 20 & 50 \\
Sex & & \\
Male & 20 & 50 \\
Female & 20 & 50 \\
Marital Status & & \\
Married & 15 & 37.5 \\
Single & 23 & 57.5 \\
Divorced & 2 & 5.0 \\
Ethnic Group & & \\
Akan & 2 & 5.0 \\
Ewe & 33 & 82.5 \\
Fante & 2 & 5.0 \\
Kotokoli & 3 & 7.5 \\
Educational Level & & \\
None & 4 & 10.0 \\
Primary & 14 & 35.0 \\
Secondary & 18 & 45.0 \\
Tertiary & 4 & 10.0 \\
Employment status & & \\
Employed & 11 & 27.5 \\
Unemployed & 29 & 72.5 \\
\hline & &
\end{tabular}

\section{State of Impairment of the respondents}

Majority $37(92.5 \%)$ of the study population are deaf (hearing and speech impaired) with a few $3(7.5 \%)$ being hard of hearing (Table 2).

Table 2: State of Impairment

\begin{tabular}{ccc}
\hline & Frequency $\mathrm{n}=(40)$ & Percentage $(\%)$ \\
\hline Hard of hearing & 3 & 7.5 \\
Deaf & 37 & 92.5 \\
\hline
\end{tabular}

\section{Current and preferred mode of communication in accessing healthcare}

Out of the 22 participants involved in the face to face interview, majority $20(90.9 \%)$ of them depend on gestures, and family member or friend's assistance to communicate in their pursuit of healthcare. However, 
few $2(9.1 \%)$ of them use sign language, and writing as a way of communication, whiles $1(4.5 \%)$ adopts to signing and speaking (Table 3a). The deaf society are yearning for other modes of communication to access healthcare such as the use of interpreters $20(90.9 \%)$; However, those who prefer the use of sign language increased from $2(9.1 \%)$ that is currently being used to $21(95.5 \%)$ (Table 3b).

Table 3a: Current mode of communication used

\begin{tabular}{lll}
\hline Variable & Frequency & Percentage (\%) \\
\hline Sign language & 2 & 9.1 \\
Gestures & 20 & 90.9 \\
Relative or friend's assistance & 20 & 90.9 \\
Signing and speaking & 1 & 4.5 \\
Writing & 2 & 9.1 \\
\hline
\end{tabular}

Table 3b: Preferred Mode of Communication

\begin{tabular}{lll}
\hline Variable & Frequency & Percentage (\%) \\
\hline Using interpreters & 20 & 90.9 \\
Without interpreter & 1 & 4.5 \\
Sign language & 21 & 95.5 \\
Mixing of speaking and signing & 1 & 4.5 \\
Writing communication & 11 & 50.0 \\
I have a friend or family member with me to & 16 & 72.7 \\
interpret & & \\
\hline
\end{tabular}

\section{Experiences in accessing healthcare and reasons for repeated visits}

The deaf presented few experiences that can affect their accessibility of healthcare services and the reasons for returning to the same health facility. Out of the 22 participants involved in the face to face interview, $8(36.4 \%)$ of them have no confidence in service providers, half $11(50 \%)$ of them were not given attention whiles their concerns were being expressed, $12(54.5 \%)$ had little time to express their problems and finally, 20 (90.9\%) were not involved in decision making about their health issues (Table 4a). Reasons given for repeated visits include information given not enough 2 (9.5\%), wrong medication $8(38.1 \%)$, problem getting worse $6(27.3 \%)$, needed more medication 9 (40.9\%), and experience new case 12 (54.5\%) (Table $4 b$ ).

Table 4a: Providers attitude towards deaf client when they access healthcare

\begin{tabular}{lll}
\hline Variable & Frequency & Percentage (\%) \\
\hline Inadequate time to express problems & 12 & 54.5 \\
Less attention given when expressing concerns & 11 & 50.0 \\
Not involved in decision making & 20 & 90.9 \\
Lack of confidence in service providers & 8 & 36.4 \\
Repeated visits to the same health facility & 17 & 77.3 \\
\hline
\end{tabular}


Table 4b: Reasons for repeated visits

\begin{tabular}{lll}
\hline Variable & Frequency & Percentage (\%) \\
\hline Information given not enough & 2 & 9.5 \\
Wrong medication & 8 & 38.1 \\
Problem got worse & 6 & 27.3 \\
Needed more medication & 9 & 40.9 \\
New cases & 12 & 54.5 \\
\hline
\end{tabular}

\section{Participants perception about providers' performance}

Due to the experiences the deaf encounter when accessing healthcare, participants assessed and graded performance of the healthcare service providers. The results revealed that $3(13.6 \%)$ of the providers were performing excellent, whiles $8(36.4 \%), 6(27.3 \%)$, and $5(22.7 \%)$ of the providers performed very good, good, and average respectively (Figure 1).

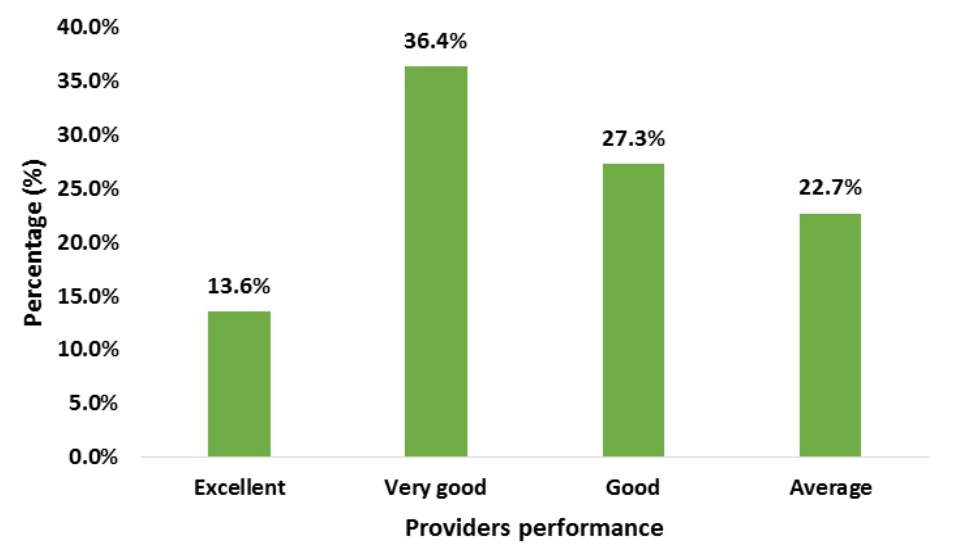

Figure 3: Perception of providers’ performance Results from Focus Group Discussions 
Table 5: Summary of Interviews for the Deaf Clients- Focus Group Discussion (FGD)

\begin{tabular}{|c|c|c|c|c|}
\hline $\begin{array}{l}\text { Accessibility to } \\
\text { healthcare }\end{array}$ & Sub-themes & FGD 1 & FGD 2 & FGD3 \\
\hline \multirow[t]{3}{*}{$\begin{array}{l}\text { Mode of } \\
\text { communication }\end{array}$} & $\begin{array}{l}\text { Knowledge on } \\
\text { available } \\
\text { method }\end{array}$ & $\begin{array}{l}\text { Sign language } \\
\text { Interpreter } \\
\text { Writing } \\
\text { Lip reading } \\
\text { Gestures }\end{array}$ & $\begin{array}{l}\text { Writing } \\
\text { Interpreter } \\
\text { Gestures } \\
\text { Sign language }\end{array}$ & $\begin{array}{l}\text { Sign language } \\
\text { Interpreter } \\
\text { Writing } \\
\text { Gestures }\end{array}$ \\
\hline & $\begin{array}{l}\text { Current method } \\
\text { practiced }\end{array}$ & $\begin{array}{l}\text { Gestures } \\
\text { Writing communication } \\
\text { Assistance of a family member or friend. } \\
\text { Lip reading }\end{array}$ & $\begin{array}{l}\text { Writing } \\
\text { Gestures } \\
\text { Assistance of family member or friend. }\end{array}$ & Gestures \\
\hline & $\begin{array}{l}\text { Preferred } \\
\text { method }\end{array}$ & $\begin{array}{l}\text { Sign language (staffs should be trained) } \\
\text { Formal interpreter } \\
\text { Writing communication }\end{array}$ & $\begin{array}{l}\text { Interpreter } \\
\text { Writing communication }\end{array}$ & $\begin{array}{l}\text { Sign language (all staff be trained) } \\
\text { Interpreter }\end{array}$ \\
\hline $\begin{array}{l}\text { Providers attitude } \\
\text { towards deaf }\end{array}$ & & $\begin{array}{l}\text { Some of the providers are more supportive } \\
\text { and render special care on realizing the client is } \\
\text { deaf. } \\
\text { Providers are more comfortable when there } \\
\text { is someone to assist the client (deaf), otherwise } \\
\text { most providers tend to delay in rendering } \\
\text { services to them. } \\
\text { When the deaf is able to read, the providers } \\
\text { attend to them well as compared to an illiterate } \\
\text { deaf who goes to the facility without assistant. } \\
\text { Little attention is given when admitted } \\
\text { because they don't know how to communicate } \\
\text { during reviews. } \\
\text { Unable to ask questions since there is this } \\
\text { communication break. }\end{array}$ & $\begin{array}{l}\text { Doctors/nurses relationship with the deaf } \\
\text { patients is quite a challenge since they are } \\
\text { given minimum attention at some times by } \\
\text { focusing more on the hearing clients. } \\
\text { Communicating through writing } \\
\text { becomes the only favorable method for the } \\
\text { providers, but this is not in the case of the } \\
\text { deaf since they cannot understand some of } \\
\text { the words written even if they can read and } \\
\text { write. } \\
\text { The deaf are unable to ask questions as } \\
\text { the providers do not understand sign } \\
\text { language and this leave the deaf with } \\
\text { unclarified thoughts concerning their } \\
\text { health. }\end{array}$ & $\begin{array}{l}\text { Much confusion is caused since } \\
\text { they can't hear when they are being } \\
\text { called and this results in delays of the } \\
\text { deaf client because the providers end } \\
\text { up attending to later clients who are } \\
\text { hearing before attending to deaf client. } \\
\text { Many a times because the } \\
\text { providers don't understand the deaf } \\
\text { language, the doctor for example talks } \\
\text { to other colleagues to assist to enhance } \\
\text { treatment procedures. } \\
\text { The nurses end up just pointing } \\
\text { and not directing them to the next unit } \\
\text { to visit. This poses a significant } \\
\text { problem for the deaf not knowing } \\
\text { where to go for the next service, } \\
\text { hence, sort to asking other clients they } \\
\text { meet for clearer direction. }\end{array}$ \\
\hline $\begin{array}{l}\text { Barriers to healthcare } \\
\text { accessibility }\end{array}$ & & $\begin{array}{l}\text { Delays in the health centers due to favoring } \\
\text { hearing of clients. }\end{array}$ & $\begin{array}{l}\text { Discrimination } \\
\text { Financial difficulty }\end{array}$ & Discrimination \\
\hline
\end{tabular}


From the above table thematic analysis of the focus group discussions with the participants' results in three broad results, which are presented below.

Communication Experiences of the speech and hearing impaired in Accessing Healthcare in Hohoe municipality.

From the FGDs, it was apparent that the deaf in accessing and utilizing healthcare employ a mix of different communication strategies but have three major broad communication experiences including communication through relatives/friends, and the use of interpreters.

\section{a) Gestures}

This was identified as the dominant mode of communication in accessing and utilizing healthcare in Hohoe Municipality by the deaf. This is usually accompanied with other mode of communication to enhance clarification. Gestures are employed by deaf in expressing their health issues since this group (relative/ friends) do not understand the sign language, the later in turn relay the health issues to the health provider during consultations.

I use two methods, one I use gestures sometimes, two because I can read and write, I write my problems to the doctor and writes the medication and give me the medication [FGD 16]

b) Communication through relatives/Friends

Majority of the FGDs participants alluded to employing the assistance of their relative's/family members whenever they visit health facilities for healthcare. However, these relatives/ friends cannot use the sign language in communicating to the deaf so they result in using gestures in communication. These are due to the fact that there are no interpreters.

he cannot understand me. he asks me to sit aside. I sit there for a long time and he attends to other hearing client since he can understand them. Sometimes when my brother or sister is not there and I have to go alone to the hospital I call a hearing friend of mine to assist me. I discuss what my problem is with him he then discusses with the doctor [FGD 13].

When am sick I tell my parents what my problem is. They assist me to the hospital and explain to the doctor on my behalf. They give me medication and I get well. I communicate my problems to my mother using gestures since she does not understand sign language [FGD 11] When I was young a relative assisted me but now I go alone. If brother is available, he does all the talking with the provider. The providers understand when I write to them [FGD 6].

She tells her mother she is sick by gestures. Her mum buys drugs from the pharmacy, she takes and gets better, so she does not go to the hospital [FGD 4].

Father goes with me to the hospital and communicates the problem to 
the providers. I communicate my problems to my parents through gestures [FGD 3].

Parents assist me to the hospital, does the communication, I am given drugs and I get well. I communicate my problems to my relatives through gestures [FGD 2].

From the above excerpts, it is quite clear that while family assistance is crucial in the communication experience of the deaf in accessing and utilizing healthcare, it has the potential of self-medication, which could affect the health of the deaf. As indicated by FGD 4, the client does not go to hospital for diagnosis of the sickness but depends on what medicine the mother provides.

Again, while it is a significant mode of communication in terms of accessing and utilization experience, the challenge here is that proper diagnoses and treatment of what the deaf suffers from depends on the ability of friends or relatives to describe the problem very well to the understanding of the healthcare providers.

c) communication through writing

This is the second most dominant communication experienced by the deaf in accessing and utilization of health services in the municipality. This communication experience as per respondents' view, entails writing down on a piece of paper how they feel. This is then passed on to the healthcare provider, who in turn does the diagnosis and write down the feedback for the patient to read. Treatment involved is communicated through same. It came up through the FGDs that two different experiences are obtained in this communication mode: - the illiterates and literates. This is explained in the following extracts:

We have two categories of deaf, some attended school and can read; some are illiterate and cannot read. The literate can respond to the doctor through writing but the illiterate who has not been to school cannot read and becomes difficult to communicate. If doctor question me by speaking I tell him, I am a deaf so I want to write, then he gives me a paper to write and the discussion is done through writing without a problem [FGD 7]

If he (doctor) ask I don't understand, he ask if I can write which I agree to, so we communicate by writing [FGD 9].

I use writing in communicating but when I do not know how to write a particular thing, I use gestures to express it [FGD 12]

Overall, the implications of this communication experiences are that the health seekers (deaf) are often not able to ask questions even if they want to, since it is often difficult for the service providers to understand sign 
language. Writing communication also post the challenge when the deaf do not understand some of the words written by the providers or they cannot express themselves well in writing which interferes with treatment. This is especially so, where the deaf visits the facilities on their own without relatives accompanying them, where they are not able to read and write and where there are often no interpreters of sign language.

d) Use of interpreters

Focus group discussants pointed to this communication strategy as their preferred mode of communication in accessing and utilizing healthcare services. However, it was very clear that in terms of experience, this is the one they have experienced really less, with the reason being that there are no interpreters in health facilities in the municipality. Alternatively, there are no sign language or interpreters nearby, whose services could be employed, whenever they visit health facilities as seen in the following quotes:

Not easy have interpreters. Maybe interpreter is far and I am sick, I can't have access to the interpreter [FGD 7].

Past, time, nurse practice in school sign language. A few nurses knew sign language. Sometimes after work I meet some of them and they help by interpreting to me. Sometimes they are not there then I sort to writing to the provider [FGD 9].

Focus Group Discussant 7 was clear that up till now there is no interpreter of sign language in health facilities in the municipality. Indeed, this is an indictment on the health system that aims at making health accessible and available to all. It also highlights the need for policymakers to walk the talk in considering the physically challenged and minorities in health policies formulations.

(e) Sign language

Sign language is the basic language for the deaf and it came out as the preferred mode of communication by the deaf. Therefore, teaching of health staff on basic sign language will enhance its usage as recommended by the respondents. This can also be achieved by teaching sign language in all health training schools to expose both medical and other paramedics to the language before they start working.

\section{Providers' attitudes towards deaf}

Experiences faced by clients play a significant role in their accessibility of healthcare and this was evident from the responses of the client. The major challenges identified were disparity, discrimination, delays and less attention given when expressing their concerns and is evidently represented below.

When am in a queue and it's my turn and the doctor realizes that I 
cannot hear, he writes to me but because I cannot write back, he asks me to sit aside and attends to other hearing clients [FGD 13].

Doctor does not pay attention when am expressing my problems but rather ends up talking with their colleagues. The nurse writes some few things down and the doctor prescribe drugs for me [FGD 15].

Sometimes when we are called, we don't hear, and we are being given direction to go to the next office, the providers just point to the direction and we get confused [FGD 18].

When there is a queue the nurses upon knowing I am a deaf, they attend to the other hearing clients that came after me. They attend to me last. It is difficult [FGD 17].

When there is a queue and am being delayed, I ask them why and inform them that I have been here for long. When am trying to tell them where I am in the queue, it comes a problem [FGD 13].

Some healthcare providers provide the necessary care for the clients despite their challenge and this was equally captured by the sayings of a respondents.

Not really because sometimes when I go to the hospital and put down my card and sit for my turn, the nurse come by and mention names of which I can't hear because I am deaf. I later alert them and make them aware am a deaf and they apologize for delays and attend to me [FGD 19].

If the doctor or nurses does not know that am a deaf or there is a deaf, it's better for the deaf to alert them when I do that, he calls me before even attending to other people [FGD 16].

There should be two different queues one for hearing and other for the deaf. When one deaf is attended to, one hearing should also be attended to in that order [FGD 18$].$

\section{Potential Barriers to accessing and utilization of healthcare services}

Challenges of communication is a form of barrier that exist dominantly among the deaf client in seeking healthcare. Though, sometimes the clients wish to ask further questions for clarification, they are not able to do so because service providers do not understand sign language. Deaf prefer sign language or interpreters since writing communication sometimes poses a challenge, and affect access and utilization.

Past, time, nurse practice in school sign language. A few nurses knew sign language. Sometimes after work I meet some of them and they help by interpreting to me. Sometimes they are not there then I sort to writing to the provider [FGD 9].

Yes, have problem. Maybe doctor will say a word hard to understand. Example when he writes ANESTHETIC I would not be able to 
understand exactly so need interpreter to help [FGD 7].

Discrimination also contributes to the challenge of accessibility. The deaf experiencing neglect when visiting health facility reduces their enthusiasm to call on the same facility when the need arises again. On this note, they turn to seek medical advice and possibly treatment outside the medical setting.

the thought that I will not be understood because they do not understand sign language. They attend to clients who can hear and neglecting us (deaf). I had an experience where a nurse told me to sit as the last client just because I cannot speak. It causes problems [FGD 22].

A couple visited a hospital and gave this concern quoted below the doctor upon realizing we were deaf told us to go out of the consulting room asking why we cannot hear or speak. I calmly came out sad but then another doctor attended to us later on. I was very sad [FGD 19].

The challenge of misunderstanding whiles expressing concerns, prevents the deaf from assessing healthcare. The feeling that the doctors or caregivers will not understand the problem causes their hesitance in accessing healthcare. Even when there is an assistance from a relative or friend, it is still troubling to know that the assistant might not be relaying the right information or describe the sickness to the providers since they themselves do not understand the sign language. Inability to communicate effectively may lead to wrong diagnosis and treatment.

I have a problem, one experience. My close friend, he can read and write, he was very sick and went to the hospital but communicated to the doctor through writing but the doctor did not really understand what my friend wrote and prescribed a wrong drug, later my friend died. It happened because the doctor did not really understand, we really need an interpreter [FGD 7].

The economic status of the study participants has an effect on their accessibility to healthcare, and it is so in this study because a high number of the respondents were unemployed contributing to their low economic status that affected the health seeking behavior. Although some have the National Health Insurance Scheme (NHIS) card, they still resort to asking friends and relatives for treatment (self-medicate) because they cannot afford the finance needed for the health care at the centers. 


\section{Discussion}

The study revealed that communication experiences of this minority group of hearing impaired clients were difficult which resulted in them receiving uneven healthcare as compared to the general population because there were either no certified trained interpreters or qualified trained health care providers. This has resulted in deaf patients experiencing disparity, discriminations, neglect, delays and frustration in receiving healthcare which were expressed in their perspectives. These experiences are similar to other reports from other studies (Smeijers et al, 2009, Pereira et al, 2010, Sirch et al, 2017).

The deaf patients encountered communication challenges in assessing healthcare in Hohoe municipality because providers do not understand sign language the main means of communication among the deaf. Therefore, most of them (90\%) reported the use of family and friends as well as gestures in communication during visits to the hospital. The other modes of communication identified in the order of dominance in this study includes sign language, writing, signing and speaking respectively. This is consistent with a research that reported Nurses inability to communicate with deaf patients hence, tend to use the same communication method with all clients irrespective of their hearing and speaking status (Hajbaghery \& Shahsavarloo, 2014). So, lip reading and the use of a family member as an interpreter were the main mode of communications used (Steinberg et al., 2005). However, the participants preferred modes of communicating at the health facility were sign language, use of interpreter or family and friends. Most of the participants were educated in the sign language it is natural for them to opt for sign language however for them appreciating the difficulty of health workers inability to understand the sign language will opt for interpreters. These findings are inconsistent with the findings of Kritzinger, who identified the use of interpreters as the most dominant mode of communication in South Africa healthcare facilities with hearing impaired clients (Kritzinger, 2011). Due to communication difficulties, it is logical to say hearing impaired clients are poorly being diagnosed and assessed when receiving healthcare which is in concurrence with the findings of Shahsavarloo and colleague (Hajbaghery \& Shahsavarloo, 2014).

Doctors/nurses relationship with the deaf patients is quite a challenge since they are given minimum attention at some times by focusing more on the hearing clients. Though some healthcare providers attempt to support when they realize the client is a deaf however, most providers delay the deaf clients in healthcare delivery since there was nobody to assist them in understanding the messages conveyed by the deaf clients. With respect to this, the providers find it more comfortable in the use of relatives/ friends assistance and writing as a way of communication. This leads to usually delays for deaf clients. 
Similarly, the work of Kyle and friends (Kyle et al., 2013), identified that harsh attitudes being meted out to deaf patients by certain providers in the UK for example more deaf clients frequently languish in waiting areas not knowing that their names have been called. However, the study showed that most of deaf clients re-visit the health facility for clarity in the use of their medicines, wrong medication and information. These challenges often leads them in a state of hesitance in accessing healthcare.

Although the use of family or friend and interpreter seem better approach to communication it comes with its challenges. Since health knowledge is important to adequately communicate both the deaf and his/her assistant be deficient, the assistant could relay their own thought of understanding to the provider. A study by Blake and friends also agreed with the findings of this study that deaf clients acquire healthcare knowledge from friends who may not have access to the correct information either. This inaccurate information leaves the Deaf with misunderstandings and misconceptions which can have a long-term impact on their health (Blake, Tucker, \& Glaser, 2014).

In spite of the fact that, deaf and hard to hearing patients reported difficulties in communicating however rated the health facility in the municipality to be doing well which shows that they appreciate the fact that these providers were not adequately trained to understand them and also obey the local culture you don't say ill of a doctor these because in the FGD they reported of discrimination, rudeness and general disparity have been the altitude of the health care providers towards them. It also interesting that they complain of financial constraint since health insurance is in full operation for the poor to access health however certain medications not available from the public supplier has to be purchased without a refund and money for transport could be the reasons for the reported financial constraints. This is similar to reports that the ability to seek care, the ability to care for the health expenses, ability to engage and the ability to reach the healthcare providers without any discrimination contribute to the low and poor accessibility of healthcare by the deaf (Levesque et al., 2013)

Generally, in healthcare delivery language deprivation and associated difficulties in skillful expressions can contribute to serious misunderstandings and deafness definitely creates communication barriers in health care setting (Woodcock \& Pole, 2007, Kuenburg, A. et al, 2016).

\section{Conclusion}

Communication between patients and their healthcare providers is very essential in health seeking, but this is usually difficult among hearing impaired clients especially without certified interpreters at hand and untrained healthcare providers. As result hearing impaired patients accessing quality 
health is uneven and frosted with much frustrations. Therefore, barriers hindering their accessibility to healthcare should be addressed effectively if health for all is to be achieved and fulfilling the fundamental human right to health.

\section{Recommendations}

Ghana Health Service (GHS) in collaboration with Ministry of Health $(\mathrm{MOH})$ should provide specially trained personnel who will serve as interpreters in each health facility.

In order to enhance the use of sign language, policy should be directed and enforced for all staff to acquire the necessary education on basic sign language within the working environment and during their training school sessions.

The GHS with partnership with $\mathrm{MOH}$ and other agencies should provide special cards or identifications order to boost easy and fast identification of deaf clients on their visit to a health facility.

Ghana Education Service should consider introducing basic sign language studies in the basic, second cycle and tertiary levels so that graduates at each level will be equipped with basic sign language communication.

The government should provide more schools for the deaf in various regions of the country in order to reduce illiteracy level among the deaf so they can also express themselves well in the sign language and writing.

The leaders of the association for the deaf should promote and encourage the deaf to go to health facilities with their own interpreters/ relative to assist, if not, the deaf on arrival should create awareness of their presence to notify the providers they are deaf.

\section{References:}

1. Andrade, P. C. (2010). Communication and Information Barriers to Health Assistance for Deaf Patients, (1).

2. Barnett, S. (1999). Clinical and Cultural Issues in Caring for Deaf People, 31(1).

3. Barnett, S. (2002). Communication with Deaf and Hard-of-Hearing People: A Guide for Medical Education, 694-700.

4. Blake, E., Tucker, W., \& Glaser, M. (2014). Towards Communication and Information Access for Deaf People, (54), 10-19.

5. Breu, F., Guggenbichler, S., \& Wollmann, J. (2004). Common Causes of Hearing Loss: For Parents \& Families. Vasa.

6. Chaveiro, N., Porto, C. C., \& Barbosa, A. (2009). Patients and The Doctor, 75(December 2006), 2007-2010.

7. Diamond, L. C., Schenker, Y., Curry, L., Bradley, E. H., \& Fernandez, A. (2008). Getting by: Underuse of Interpreters by Resident 
Physicians, 256-262. Http://Doi.Org/10.1007/S11606-008-0875-7

8. Hajbaghery, M. A., \& Shahsavarloo, Z. R. (2014). Assessing The Nursing and Midwifery Students Competencies in Communication with Patients with Severe Communication Problems, 3(2).

9. Harmer, L. (1999). Healthcare Delivery and Deaf People: Practice, Problems, and Recommendations for Change. Journal of Deaf Studies and Deaf Education, 4(2), 73-110. Http://Doi.Org/10.1093/Deafed/4.2.73

10. Helena, A., Cardoso, A., Del, A., Communication, P. D. E., Su, D., \& Salud, A. D. E. (2006).

11. Perception of Persons with Severe or Profound Deafness, 14(4), 553560.Hohoe Municipality. (2014).

12. Joshua Project (2013). The Deaf Community of Ghana: The Ghanaian Sign

13. Language Community -Have They Heard The gospel? 000.

14. Kritzinger, J. (2011). Exploring The Barriers and Facilitators to Healthcare Services and Health Care Information for Deaf People in Worcester by, (December).

15. Kuenburg, A., Fellinger, P., \& Fellinger, J. (2016). Healthcare Access Among Deaf People, 1-10. http://Doi.Org/10.1093/Deafed/Env042

16. Kyle, J., Sutherland, H., Allsop, L., Ridd, M., Emond, A., Cunliffe, M., \& Ackerman, J. (2013). Deaf Health Analysis of the Current Health and Access to Healthcare of Deaf People in the UK.

17. Levesque, J., Harris, M. F., \& Russell, G. (2013). Patient-Centred Access to Healthcare: Conceptualizing Access at The Interface of Health Systems and Populations, 1-9.

18. Marschark, M., \& Carol, M. (2007). Understanding Communication among Deaf Students Who

19. Sign and speak; A Trivial Pursuit? 152(4).

20. Nursing Practice Review (2014). Meeting Deaf Patients' Communication Needs, 110(49), 12-15. Retrieved from www.nursingtimes.net / Vol 110 No 49 / Nursing Times 03.12.14 on $3^{\text {rd }}$ January 2017.

21. Peterson-Besse, J. J., Walsh, E. S., Horner-Johnson, W., Goode, T. D., \& Wheeler, B. (2014).

22. Barriers to Healthcare among People with Disabilities who are Members of Underserved Racial / Ethnic Groups a Scoping Review of the Literature, 52(10), 51-63.

23. Scholarworks, S., \& Tarmey, A. H. (2007). A Relational-Exploratory study: How Attitudes

24. towards Deafness Affect Quality of Behavioral Health Services Provided to the Deaf / Hard of Hearing Client. 
25. Shuler, B. G. K., \& Mistler, L. A. (2013). Bridging Communication Gaps.

26. Shuler, B. G. K., \& Mistler, L. A. (2014). With the more than Signing: (March), 20-27.

27. Singh, V. (2015). Hearing in India: All Aspects, 5(1).

28. Rodda, M \& Eleweke, C. J. (2002). Providing Accessible Services to Minority Ethnic Deaf People: Insights A Study in Alberta, Canada, (5).

29. Steinberg, A. G., Barnett, S., Meador, H. E., Wiggins, E. A., \& Zazove, P. (2005). Po Pulations at Risk, 14620(November 1999), 260-266. Http://Doi.Org/10.1111/J.1525-1497.2006.00340.X

30. Steinberg, A. G., Lipton, D. S., Ph, D., Eckhardt, E. A., Goldstein, M., Ph, D., \& Sullivan, V. J.

31. (1998). The Diagnostic Interview Schedule for Deaf Patients on Interactive video: A Preliminary Investigation, (November), 16031604.

32. Steinberg, A. G., Sullivan, V. J., \& Loew, R. C. (1998). Cultural and Linguistic Barriers to Mental Health Service Access: The Deaf Consumer's Perspective. American Journal of Psychiatry, 155(7), 982-984. Http://Doi.Org/10.1176/Ajp.155.7.982

33. Sirch, L., Salvador, L., \& Palese, A. (2017). Communication difficulties experienced by deaf male patients during their in-hospital stay: findings from a qualitative descriptive study. Scandinavian journal of caring sciences, 31(2), 368-377.

34. Smeijers, A. S., \& Pfau, R. (2009). Towards a treatment for treatment: On communication between general practitioners and theirdeaf patients. The Sign Language Translator and Interpreter, 3, 1-14

35. Pereira, P. C., \& Fortes, P. A. (2010). Communication and information barriers to health assistance for deaf patients. American Annals of the Deaf, 155, 31-37. doi:10.1353/aad.0.0128

36. Woodcock, K., \& Pole, J. D. (2007). Health profile of deaf Canadians: Analysis of the Canada Community Health Survey. Canadian Family Physician Médecin De Famille Canadien, 53, 2140-2141.

37. WHO. (2011). World Report On Disability 2011. American Journal of Physical Medicine Rehabilitation Association of Academic Physiatrists, 91, 549. 